\title{
Relationship between the Initial Fracture Stress and Fatigue Limit-Simple Prediction Method of Tensile Fatigue Limit of Composite
}

\author{
Y. Imai, K. Nishitani, G. Fortin, A. Ohtani, H. Hamada \\ Department of Advanced Fibro-Science, Kyoto Institute of Technology, Kyoto, Japan \\ Email: kitktkshym24@gmail.com
}

How to cite this paper: Imai, Y., Nishitani, K., Fortin, G., Ohtani, A. and Hamada, H. (2019) Relationship between the Initial Fracture Stress and Fatigue Limit-Simple Prediction Method of Tensile Fatigue Limit of Composite. Open Journal of Composite Materials, 9, 338-354.

https://doi.org/10.4236/ojcm.2019.94021

Received: July 23, 2019

Accepted: September 21, 2019

Published: September 24, 2019

Copyright $\odot 2019$ by author(s) and Scientific Research Publishing Inc. This work is licensed under the Creative Commons Attribution International License (CC BY 4.0).

http://creativecommons.org/licenses/by/4.0/

\section{c) (i) Open Access}

\begin{abstract}
This article presents an experimental study that clarifies the relationship between the initial fracture stress and fatigue limit of glass fiber reinforced unsaturated polyester resin specimens with a laminated structure taken from a pultruded square pipe. Quasi-static bending and tension tests are performed with acoustic emission (AE) measurements to identifying the occurrence of initial fracture during testing. $\mathrm{AE}$ and observation results have clarified the occurrence of initial fracture was detected by maximum acoustic energy values and corresponding fiber breakage in the unidirectional (UD) bundles. Moreover, the ratio of initial fracture stress to ultimate strength is $32 \%$ in bending and $26 \%$ in tension, when comparing stress and strains on the tension side of the UD layer. These values are in good agreement with each other and with the measured tensile fatigue limit when the cyclic stress is at $25 \%$ of the tensile strength. Initial fracture stress obtained by static tests is close values to the fatigue limit which will greatly contribute to the prediction of the fatigue limit.
\end{abstract}

\section{Keywords}

Initial Fracture, Fatigue Limit, Acoustic Emission Testing, Tensile Testing, Bending Testing

\section{Introduction}

Global warming is a serious problem which causes increase average temperature and sea temperature and sea-level rise. Human-made gases such as carbon dioxide, methane, nitrous oxygen give a large influence to the environment [1]. 
IPCC reported the emission of carbon dioxide from fossil fuels is said to be $58.6 \%$ in the world and about $13.1 \%$ is from transportation [2]. For this reason, the weight reduction of automobile parts has become critical. In terms of maximizing performance at a minimal weight, fiber-reinforced polymer (FRP) composites are at the fore. Compared with conventional steels, they are far superior in specific properties including bending characteristics, impact resistance, among others. While FRPs are primarily used in the automotive industry for outer panels where medium strength and high design are required, they will be increasingly applied to structural members in the future [3] [4] [5]. In order to realize this, it is necessary to guarantee the period of use as a component and to measure the characteristics of the material, the fabrication method, and the structure in consideration of fatigue characteristics. It is necessary to carry out research and development in this area.

Critical experimental investigations on the tensile fatigue behavior of composite materials have been performed in the literature. Wisnom et al. [6] investigated the fatigue behavior of pseudo-ductile unidirectional thin-ply carbon/epoxy-glass/epoxy hybrid composites. They tested specimens in static tension to determine the fragmentation initiation stress level. When the same pristine samples were tested in fatigue at stress amplitudes significantly lower than the stress initiation level, no stiffness reduction up until 105 cycles was observed as a result of being loaded well below the first carbon layer fracture strain [6]. Pandita et al. [7] studied the tensile fatigue behavior of glass plain-weave fabric composites in on- and off-axis directions. The fatigue behavior was observed to be anisotropic.

Padmaraj et al. [8] performed an experimental study on the tension-tension fatigue behavior of glass/epoxy quasi-isotropic laminates using constant amplitudes at different stress levels. Damage growth in the material was characterized by evaluating degradation in stiffness. They observed that with increasing stress amplitude levels, the number of cycles to failure was significantly reduced. They represented the static stress-strain curve as a bi-linear curve and reported that fibers normal to the loading direction failed at a lower fracture strain and that the failure strain of fibers oriented in the loading direction resulted in the final failure of the specimens [8]. Echtermeyer et al. [9] evaluated the lifetime and Young's modulus changes of glass/phenolic and glass/polyester composites under fatigue. They performed static tension and compression on the samples, and later tested their tensile and compressive fatigue properties at varying stress amplitudes. They observed that fatigue stiffness at stress amplitudes beyond the linear limit of the static stress-strain curve lose tensile stiffness slowly and linearly with the logarithm of the cycle number. The stiffness decreases to a lower value until a critical value is reached, likely due to matrix cracking. Beyond the critical value, the stiffness decreases rapidly. However, when fatigue stress amplitudes are below the linear limit of the stress-strain curve, there is an initial period before the stiffness drops, and after a slow linear decrease in stiffness with the log 
of cycle number, reduction in stiffness gradually stops. They reported that fatigue at relatively high-stress amplitudes the matrix has an influence, and at lower stresses, fatigue is dominated by the fibers. Kenane and Benzeggagh [10] performed delamination fatigue-crack growth experiments on unidirectional glass/epoxy laminates. They applied mixed-mode bending tests to characterize several cases of mixed-mode delamination under fatigue loading.

There are various fracture modes of fiber reinforced plastics, and even microscopic fractures that cannot be seen from the material surface may cause significant damage leading to final fracture. In materials testing, acoustic emission (AE) testing can be used as a method to evaluate the fracture mode and mechanism of materials. This method is well known for its applicability in the nondestructive inspection. AE consists of an elastic wave emitted when local deformation or crack propagation occurs in a material [11]. The emissions are measured when stress is applied to a material using an $\mathrm{AE}$ sensor composed of piezoelectric elements allowing to identify the type and source of failure. It is possible to measure the onset of failure during material testing in real-time. From the measurements of $\mathrm{AE}$, information such as the number, frequency, and energy of generated emissions can be obtained and based on these, it is possible to gain knowledge on the destruction of materials. The AE method has been applied successfully in the literature to identify and evaluate damage in composites. Some good examples include studies by Fotouhi et al. [12], Aggelis et al. [13], and Arumugam et al. [14]. Imai et al. investigated the quasi-static flexural properties of a pultruded glass fiber/unsaturated polyester square pipe. They reported the relationship between $\mathrm{AE}$ measurements and bending test. $\mathrm{AE}$ measurements were able to find out the initial fracture stress [15].

In this paper, we investigated the relationship between the initial fracture and fatigue limit of glass fiber reinforced unsaturated composite. AE measurement was performed to obtain fracture information on the tensile test. Tensile test and bending test were performed to clarify the fracture mechanism of laminated structures. The tensile fatigue test was conducted to clarify the relationship between fatigue properties and initial fracture stress.

\section{Materials and Test Methods}

\subsection{Materials}

Fiber reinforced unsaturated polyester resin with a laminated structure, manufactured in the form of a square pipe by the pultrusion process was used in this study. Details on the square pipe geometry and dimensions are presented in Figure 1. Experimental tests were performed on small specimens cut out from the flat sections of the laminated square pipe. As shown in the figure, the laminated structure consists of the following 5 layers: a combination of a chopped strand mat and screen type mat on the two outside layers, followed by a screen-type mat on the second layers, and unidirectional (UD) fibers oriented along the longitudinal axis of the pipe $\left(0^{\circ}\right.$ direction) in the inner-most layer. 

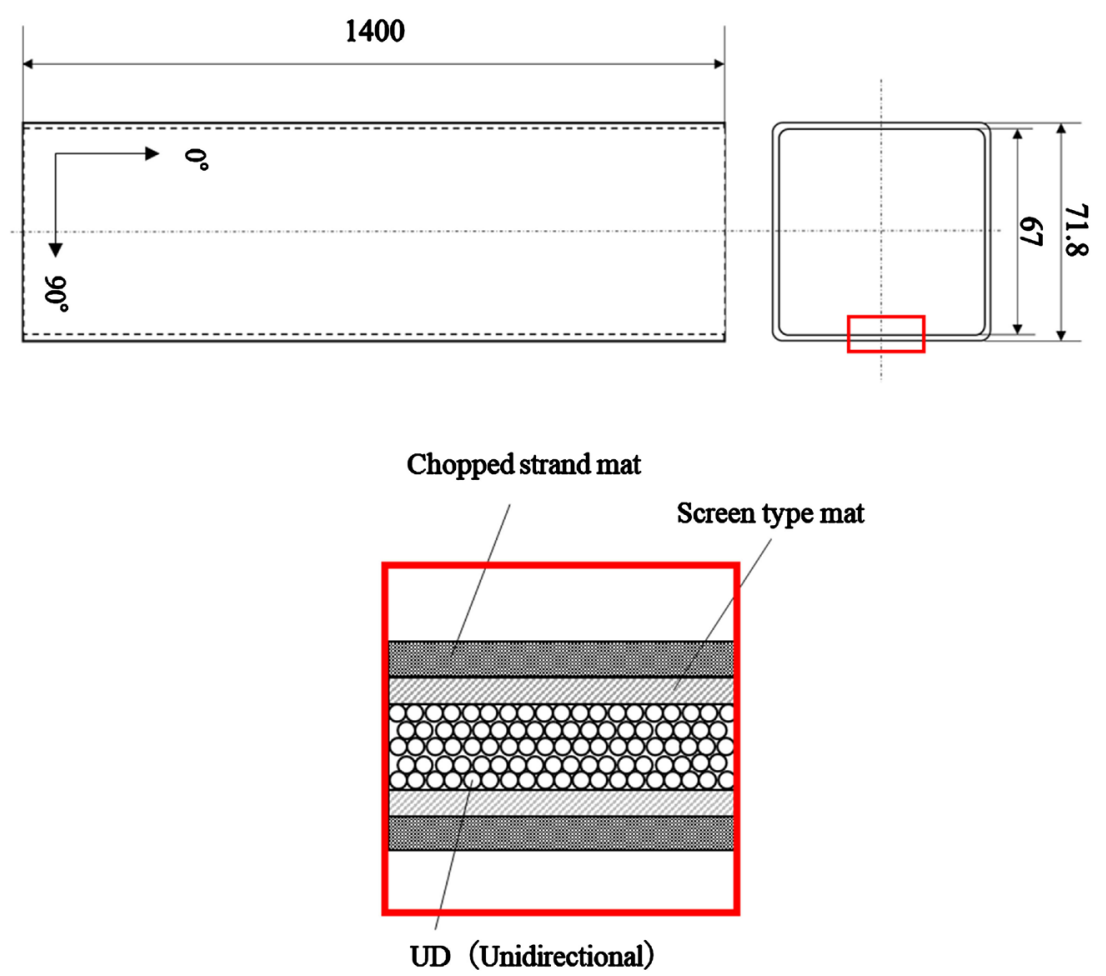

Figure 1. Square pipe geometry and laminated structure [15].

\subsection{Quasi-Static Bending Properties}

The bending test pieces were cut out from the square pipe as strips $2.4 \mathrm{~mm}$ in thickness, $90 \mathrm{~mm}$ in length, and $25 \mathrm{~mm}$ in width as shown in Figure 2. Three-point bending tests were performed using an Instron Universal Testing Machine (model 55R4206) at a displacement speed of $2.0 \mathrm{~mm} / \mathrm{min}$, span length of $60 \mathrm{~mm}$, at room temperature. For measurement of strain, a strain gauge with a gauge length of $10 \mathrm{~mm}$ (KFGS-10-120-C1-11) was used. During the bending tests, the initial damage was also evaluated using the AE method. Using an $\mathrm{AE}$ sensor (Nihon Physical Acoustics, Inc., micro-30), the AE measurement threshold was set to $55 \mathrm{~dB}$.

For the observation of fracture in the specimen, a small metallurgical microscope (Olympus, Inc., GX41) was used. In addition, in order to observe the fracture progression, the test was interrupted at displacement intervals of $0.5 \mathrm{~mm}$, and cross-sectional observation at each displacement was conducted.

\subsection{Quasi-Static Tensile Properties}

Tensile specimens were also cut out from the square pipe, with dimensions of $2.4 \mathrm{~mm}$ in thickness, $250 \mathrm{~mm}$ in length, and $15 \mathrm{~mm}$ in width as shown in Figure 3. The tensile tests were performed at a displacement speed of $2.0 \mathrm{~mm} / \mathrm{min}$, a grip distance of $150 \mathrm{~mm}$, and at room temperature. The tests were performed using strain gauges and AE sensors, and the initial damage of the material during tensile testing was evaluated. In addition, in order to observe the fracture progression, cross-sectional observations were conducted. 


\subsection{Tensile Fatigue Properties}

The shape and dimensions of the specimens used for the tensile fatigue tests were the exact same as those for the static tensile tests as shown in the previous section. A Shimadzu Corporation Servo Pulser fatigue testing machine was used (model EHF-ED10) at a frequency of $5 \mathrm{~Hz}$ which this value is commonly used in the composite material field [16] [17]. The load waveform was a sine wave, and testing was conducted at room temperature. The load conditions were determined from the tensile test results to investigate the relationship between tensile stress level and fatigue limit tensile stress level. The testing conditions were shown in Table 1 . The fatigue properties were evaluated according to the S-N diagram, and the value of cyclic stress that was repeated over $10^{7}$ times was taken as the fatigue limit.
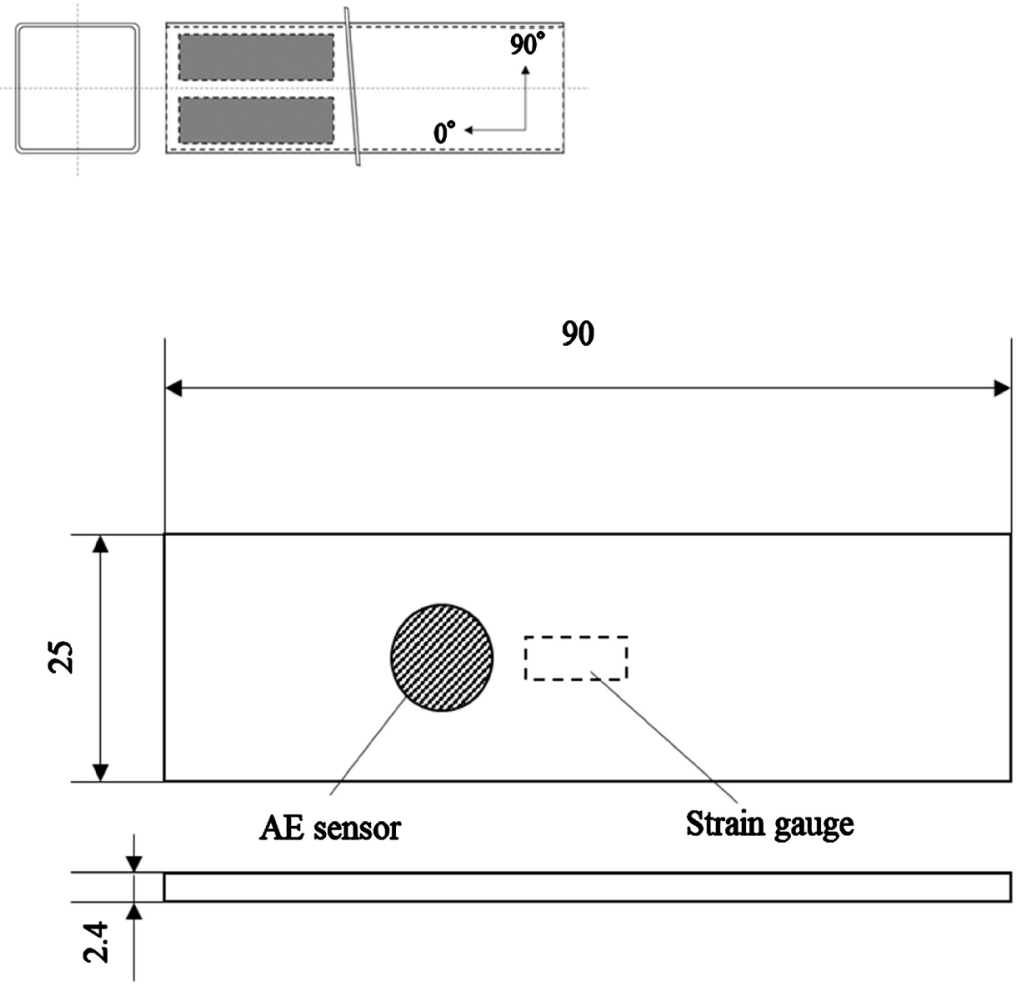

Figure 2. Specimen geometry for bending test.

Table 1. Fatigue test conditions.

\begin{tabular}{cc}
\hline Applied stress level [\%] & Tensile stress [MPa] \\
\hline 55 & 241 \\
50 & 219 \\
45 & 198 \\
40 & 175 \\
35 & 152 \\
30 & 132 \\
25 & 110
\end{tabular}



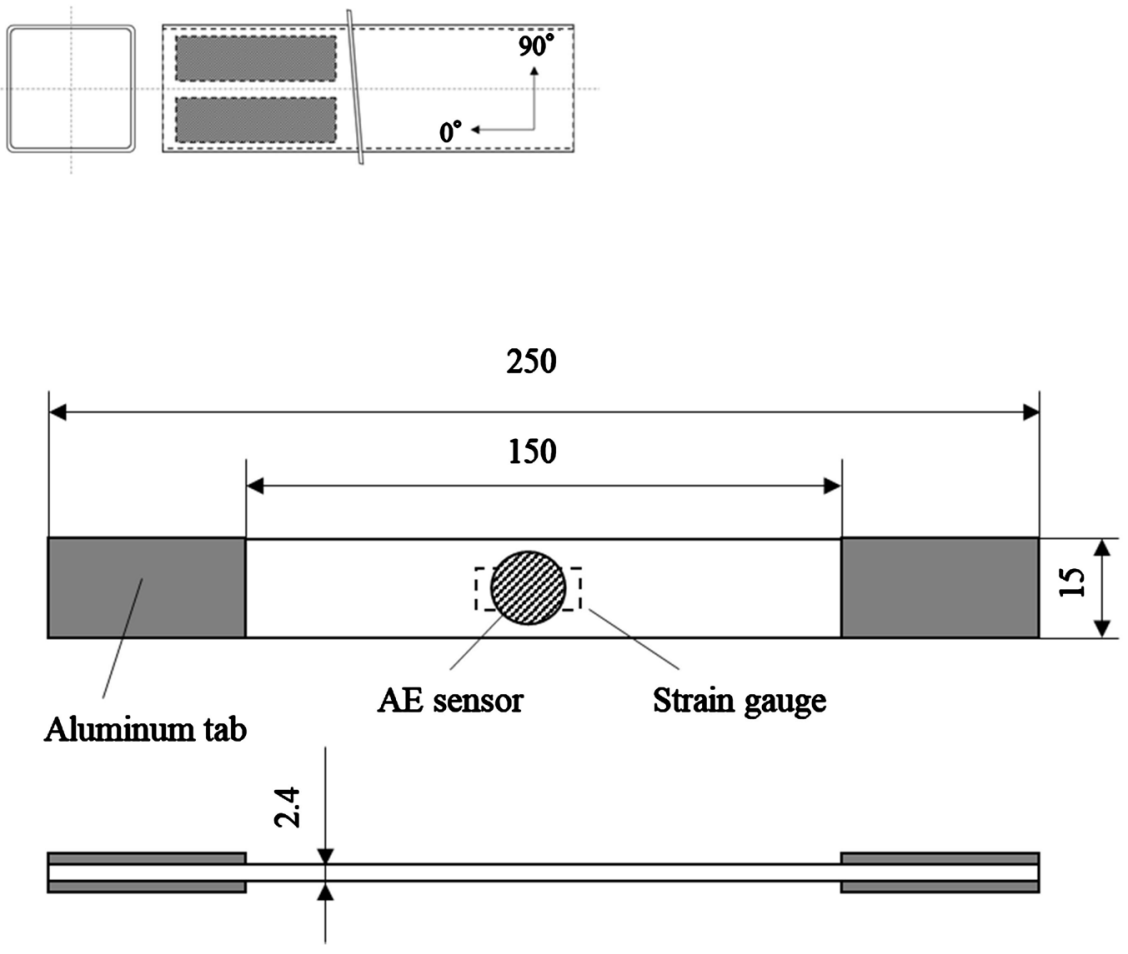

Figure 3. Specimen geometry for Tensile test.

\section{Results and Discussion}

\subsection{Bending Properties}

After the bending tests, final failure occurred on the tensile side and signs of failure on the compression side could not be observed. The bending test results are presented in Table 2, the relationship between the AE amplitude and displacement is shown in Figure 4, the $\mathrm{AE}$ energy and displacement are shown in Figure 5, and the relationship between the cumulative AE count number and displacement is shown in Figure 6. Part (a) in each figure shows the corresponding stress-strain diagram taken from a specimen. In the stress-strain diagram shown in (a), stress-strain data from other samples are not included due to broken strain gauges during testing. In (b), the stress-displacement diagram is shown.

From the stress-displacement diagram, a linear relation is observed up to a displacement of $3.0 \mathrm{~mm}$, after which it becomes non-linear until a final fracture occurs. Also, Figure 6(b) shows that in the linear region, as the displacement is increased, the number of $\mathrm{AE}$ counts increases only slightly. However, in the non-linear region, the number of $\mathrm{AE}$ counts increases significantly. Figure 4 shows amplitude values as high as $95 \mathrm{~dB}$, however, near the end of the test at final failure, the amplitude is as low as $75 \mathrm{~dB}$ and does not exceed this value. The resulting energy in Figure 5(b) shows relatively high energy values of $500 \mu \mathrm{V}$ * sec/count or more immediately after transitioning from the linear region to the non-linear region of the stress-displacement curve. In addition, the maximum energy value occurs at a displacement of $3.5 \mathrm{~mm}(\fallingdotseq$ strain 0.011$)$ and stress 


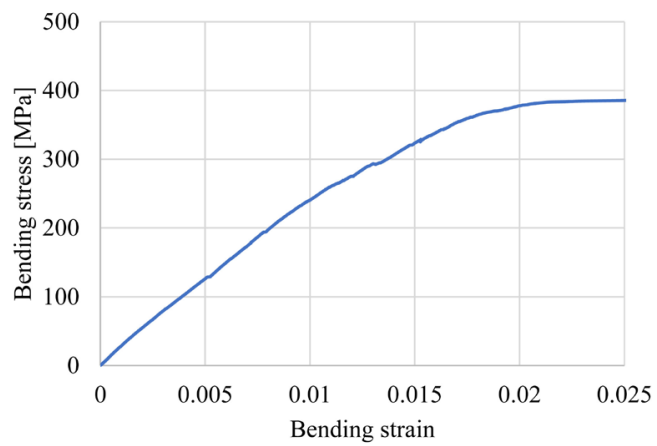

(a)

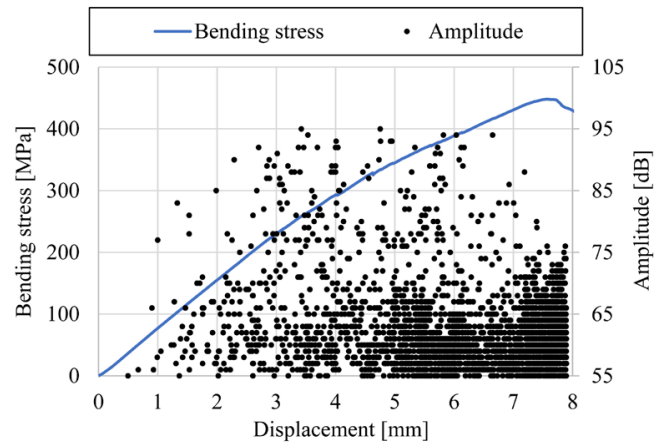

(b)

Figure 4. Results of bending test and AE amplitude. (a) Stress-Strain curve; (b) Relationship between bending stress, Amplitude and displacement.

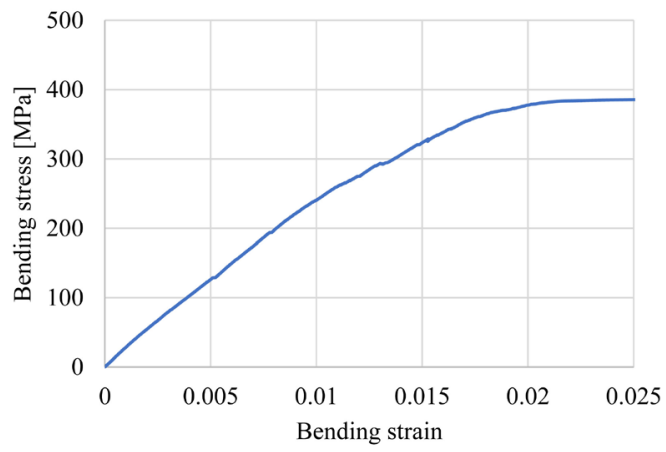

(a)

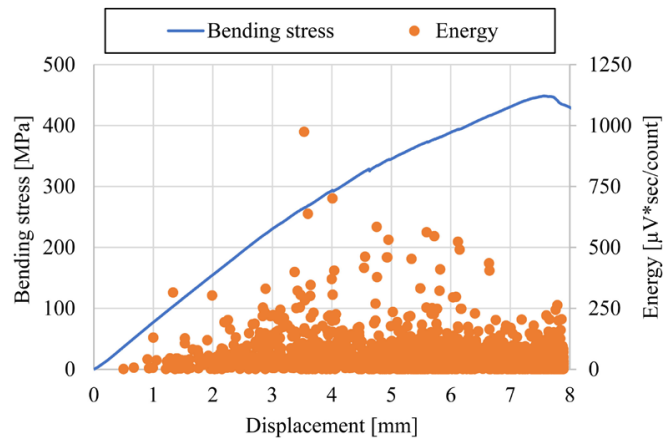

(b)

Figure 5. Results of bending test and AE energy. (a) Stress-Strain curve; (b) Relationship between bending stress, Energy and displacement. 


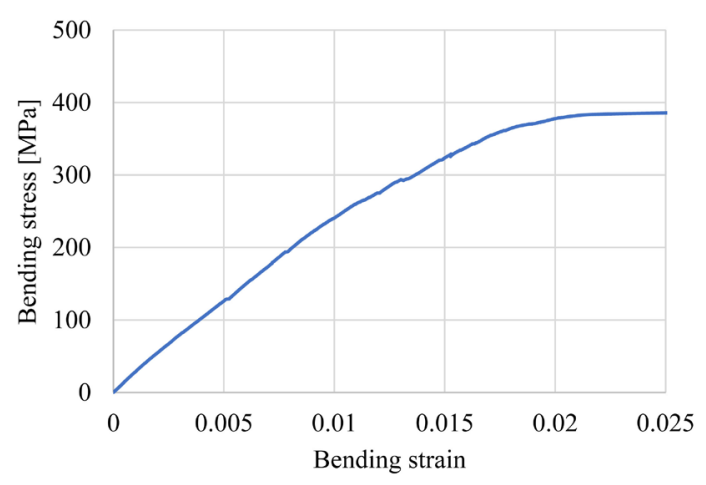

(a)

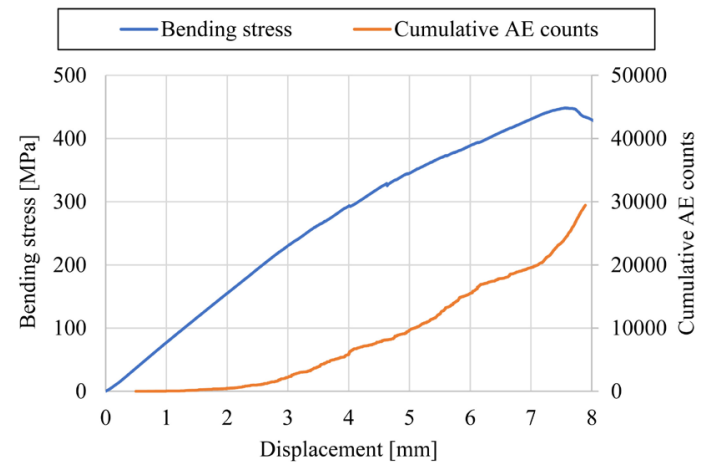

(b)

Figure 6. Results of bending test and cumulative AE counts. (a) Stress-Strain curve; (b) Relationship between bending stress, cumulative AE counts and displacement.

Table 2. Bending test results.

\begin{tabular}{ccc}
\hline Number & Bending modulus $[\mathrm{GPa}]$ & Bending strength $[\mathrm{MPa}]$ \\
\hline 1 & 19.1 & 417.2 \\
2 & 18.6 & 354.7 \\
3 & 18.7 & 409.7 \\
Ave. & 18.8 & 393.9 \\
\hline
\end{tabular}

value of approximately $265 \mathrm{MPa}$, regardless of the test piece. It is suggested that at this displacement, a fracture with relatively high energy release such as fiber breakage occurs in the specimen [18].

Figure 7 (a) shows the relationship between amplitude and displacement in the interrupted tests, and Figure $7(\mathrm{~b})$ shows the relationship between energy and displacement. In the previous bending test results, a high energy value of $500 \mu \mathrm{V} *$ sec/count or more was shown near a displacement of $3.0 \mathrm{~mm}$. In Figure 7, the individual bending stress lines and AE amplitude and energy plots were shown in a different color which indicates the test was performed with each displacement $0.5 \mathrm{~mm}$.

Figure 8 shows the results of cross-sectional observation accompanied by schematic diagrams at displacements of $0 \mathrm{~mm}, 2.5 \mathrm{~mm}, 4.0 \mathrm{~mm}$ and $6.5 \mathrm{~mm}$. A transverse crack is observed in the fiber bundle oriented in the $90^{\circ}$ layer at a 


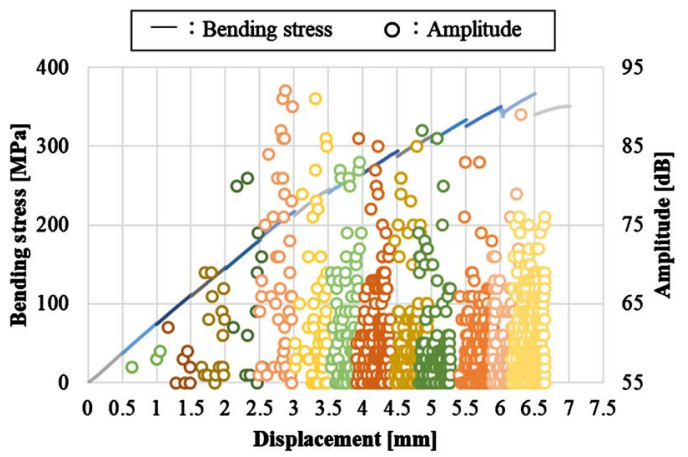

(a)

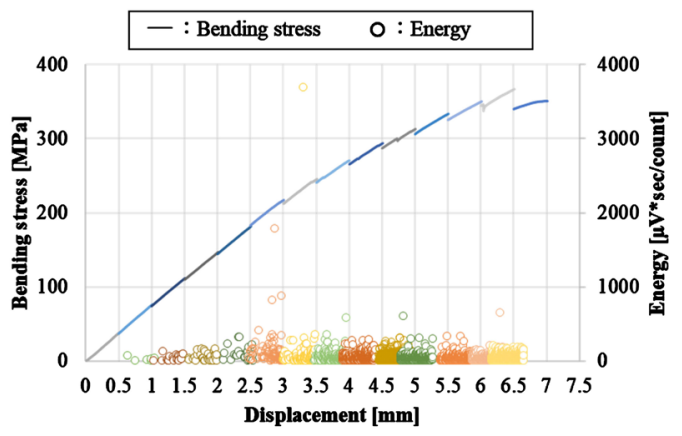

(b)

Figure 7. Results of step-by-step bending test and AE. (a) Relationship between bending stress, Amplitude and Displacement; (b) Relationship between bending stress, energy and displacement.

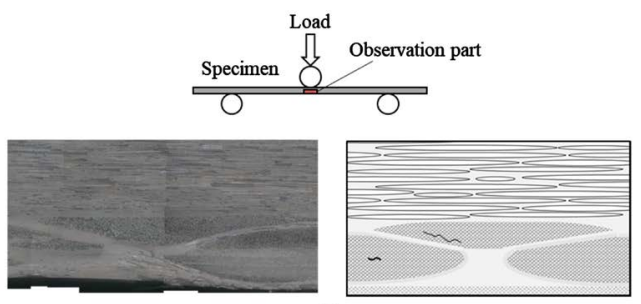

(a)
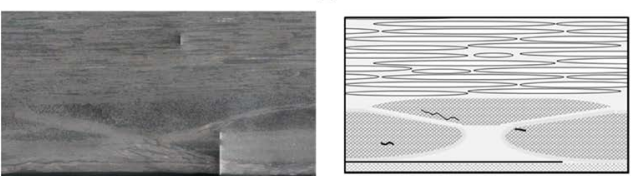

(b)
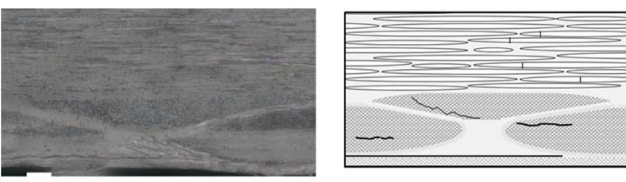

(c)
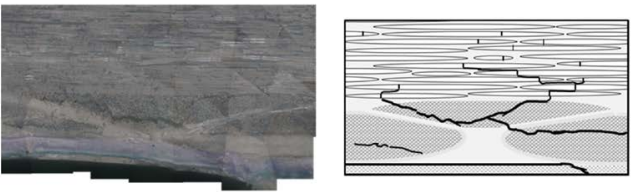

(d)

Figure 8. Cross-section observation and schematic diagram on each displacement in bending test. (a) $0 \mathrm{~mm}$; (b) $2.5 \mathrm{~mm}$; (c) $4.0 \mathrm{~mm}$; (d) $6.5 \mathrm{~mm}$. 
displacement of $0 \mathrm{~mm}$. It is considered that this is caused by the difference in curing and shrinkage parameters during the pultrusion process [19]. At a displacement of $2.5 \mathrm{~mm}$, debonding of the mat layer is observed, and transverse cracks can be seen in the fiber bundles oriented at $90^{\circ}$ in the screen type mat layer.

At a displacement of $4.0 \mathrm{~mm}$, beyond the linear to non-linear transition at a displacement of $3.0 \mathrm{~mm}$, a fracture that resulted in high released energy occurred, as seen by transverse cracking in the $90^{\circ}$ layers as well as fiber fracture of UD layers. After that, at a displacement of $6.5 \mathrm{~mm}$ prior to final failure, both types of fractures developed until the final fracture of fibers in the UD layer bundles.

Since the final breakage was caused by the fracture of fibers in the UD layer, the fiber breakage in the UD layer generated at a displacement of $3.5 \mathrm{~mm}$ is considered to be the cause of final destruction. From the above observations, the failure with a high energy value of $\mathrm{AE}$ is regarded as the initial fracture in the UD layer. The initial fracture of the UD layer in the bending test occurs at approximately $3.5 \mathrm{~mm}$ (a strain of 0.011 ) at the corresponding stress of approximately $265 \mathrm{MPa}$. In this case, the initial fracture stress is about $60 \%$ of the ultimate strength of the material.

\subsection{Tensile Properties}

As failure occurred on the tension side of the samples during the bending tests, it is considered that tensile failure contributes to the final failure, therefore tensile properties were examined carefully. Upon observing the fracture appearance following the tensile tests, final fracture of all specimens was characterized by fiber breakage of the UD layer. Tension test results are presented in Table 3, the relationship between the AE amplitude and displacement is shown in Figure 9, the $\mathrm{AE}$ energy and displacement are shown in Figure 10, and the relationship between the accumulated $\mathrm{AE}$ counts and the displacement is shown in Figure 11.

Part (a) in each figure also shows the corresponding stress-strain diagram. In the stress-strain diagram, linear behavior can be seen until the final fracture. According to Figure 11(b), the cumulative AE count number increases rapidly when the displacement reaches $1.0 \mathrm{~mm}$. Beyond that point, the cumulative number increases gradually, and then the AE count increases at approximately $3.0 \mathrm{~mm}$ of displacement. With respect to the sudden increase of the AE count,

Table 3. Tensile test results.

\begin{tabular}{ccc}
\hline Number & Tensile modulus [GPa] & Tensile Strength [MPa] \\
\hline 1 & 39.2 & 438.9 \\
2 & 36.5 & 438.0 \\
3 & 38.2 & 446.7 \\
Ave. & 37.9 & 441.2 \\
\hline
\end{tabular}




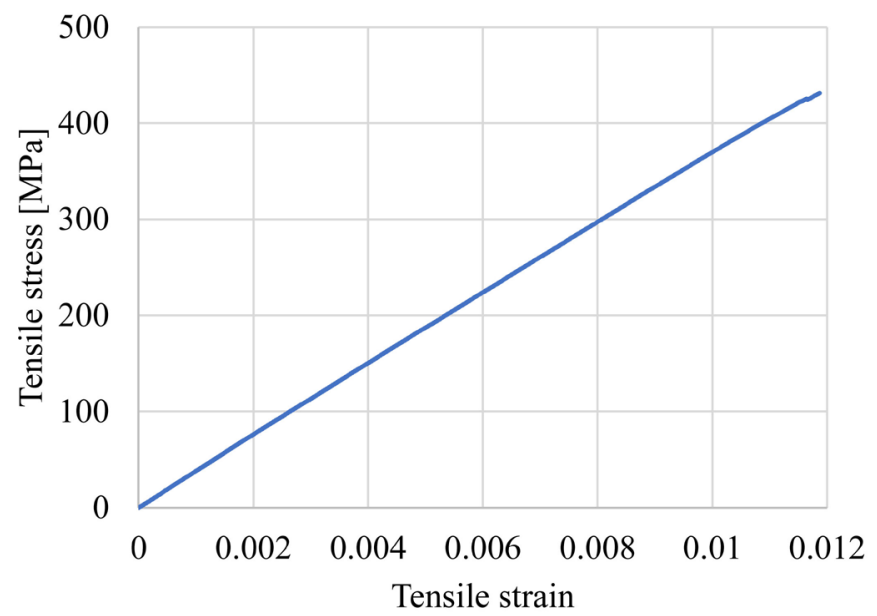

(a)

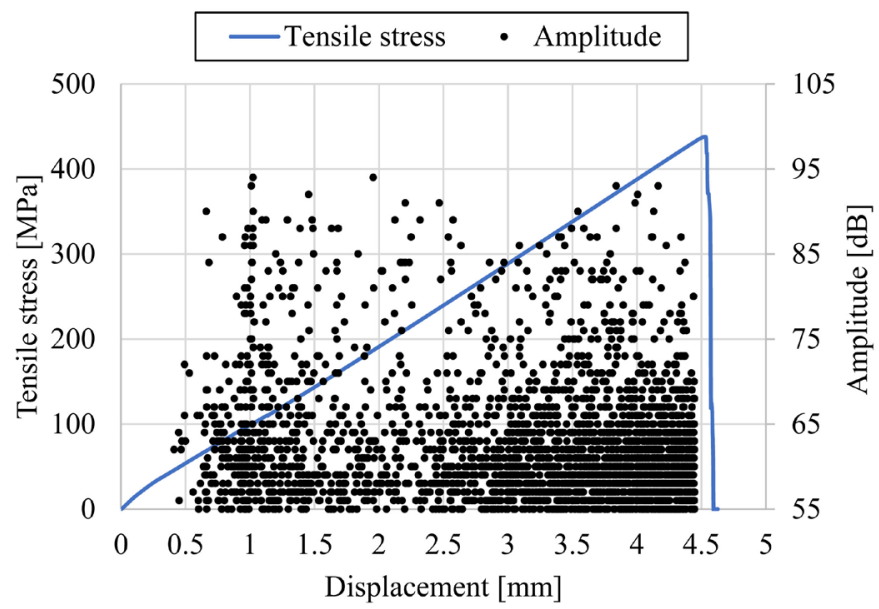

(b)

Figure 9. Results of tensile test and AE amplitude. (a) Stress-Strain curve; (b) Relationship between Tensile stress, Amplitude and Displacement.

Figure 10(b) also shows high energy values over $700 \mu \mathrm{V}{ }^{\star} \mathrm{sec} /$ count at $1.0 \mathrm{~mm}$ of displacement. At this displacement (a strain of 0.0027) and stress of approximately $100 \mathrm{MPa}$, the maximum energy values are observed. As in the bending tests, it is suggested that fracture is caused by relatively high energy release events such as fiber breakage that occurred in the test piece at this displacement [18].

In addition, in order to observe the progress and development of the fracture, cross-sectional observation of the test piece at a displacement of $1.8 \mathrm{~mm}$ was conducted. The results of cross-sectional observation of Sample A (before the test) and Sample B (displacement of $1.8 \mathrm{~mm}$ ) along with a schematic view are presented in Figure 12. According to Figure 12(a), no fracture is observed in the fiber bundles of the UD layer and $90^{\circ}$ layer before the test. However, at a displacement of $1.8 \mathrm{~mm}$ in Figure 12(b), multiple transverse cracks are observed in the fiber bundle oriented at $90^{\circ}$, and cracks are further observed in the UD layer. This is similar to the bending test observations since the final failure was 


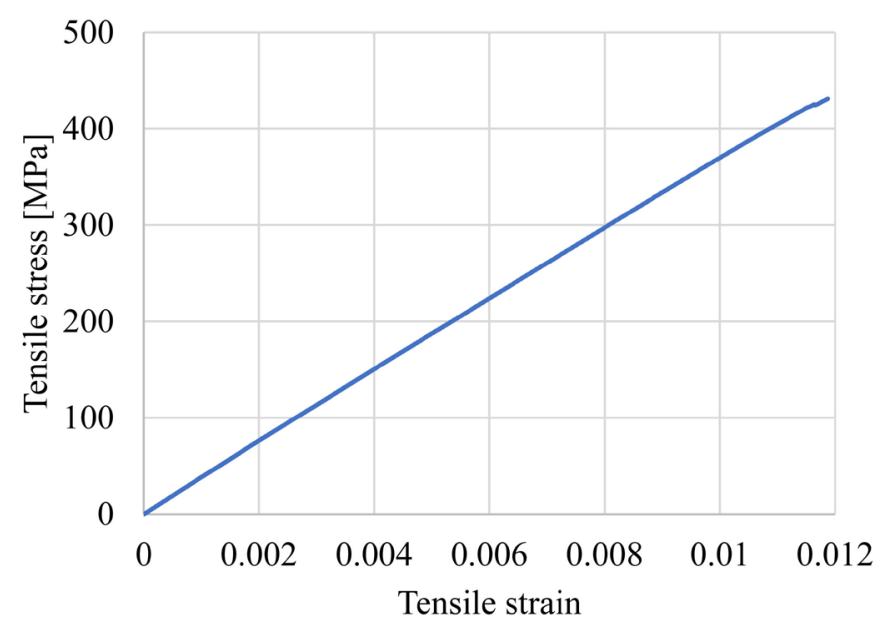

(a)

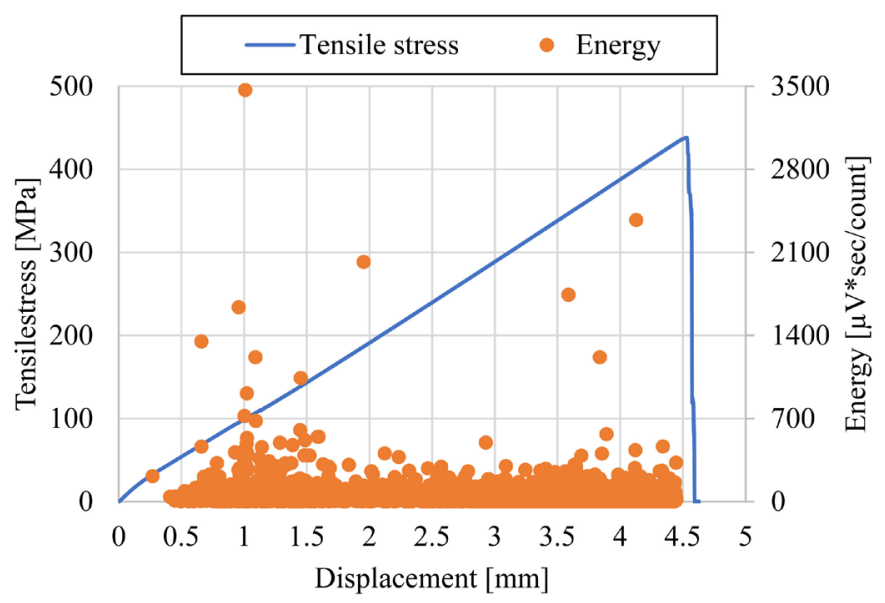

(b)

Figure 10. Results of tensile test and AE energy. (a) Stress-Strain curve; (b) Relationship between tensile stress, energy and displacement.

caused by the failure of the UD layer. The fiber breakage of the fibers from the UD layer generated at a displacement of $1.0 \mathrm{~mm}$ is considered to be the cause of final failure. From this, it is considered that the initial fracture of the UD layer during tensile testing occurred at a displacement of $1.0 \mathrm{~mm}$ (strain of 0.0027), at a stress of approximately $100 \mathrm{MPa}$, with the initial fracture stress being $26 \%$ of the ultimate strength.

As a result of observing the progress of the fracture, it was suggested that the initial fracture of the UD layer was the cause of final fracture in both the bending tests and the tension tests. The ratio of the initial fracture stress to final strength was $60 \%$ in the bending test, and $26 \%$ in the tension test. There is a significant difference between the two values. To further investigate, the strain value during the bending tests was considered.

The strain gauge attachment position of the bending test piece was on the outermost layer of the specimen, on the chopped strand mat layer. Reported strains during testing were measured on this outermost layer. Therefore, using 


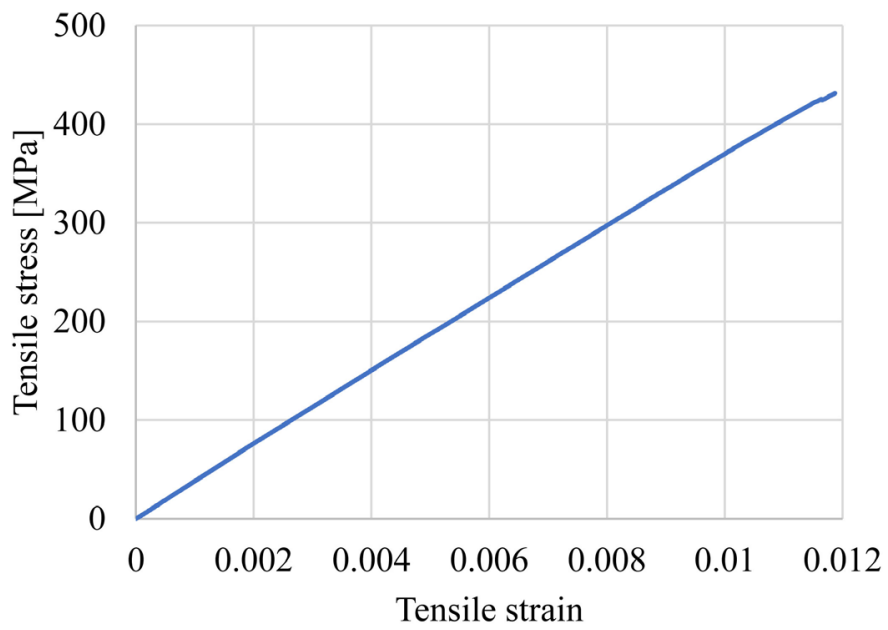

(a)

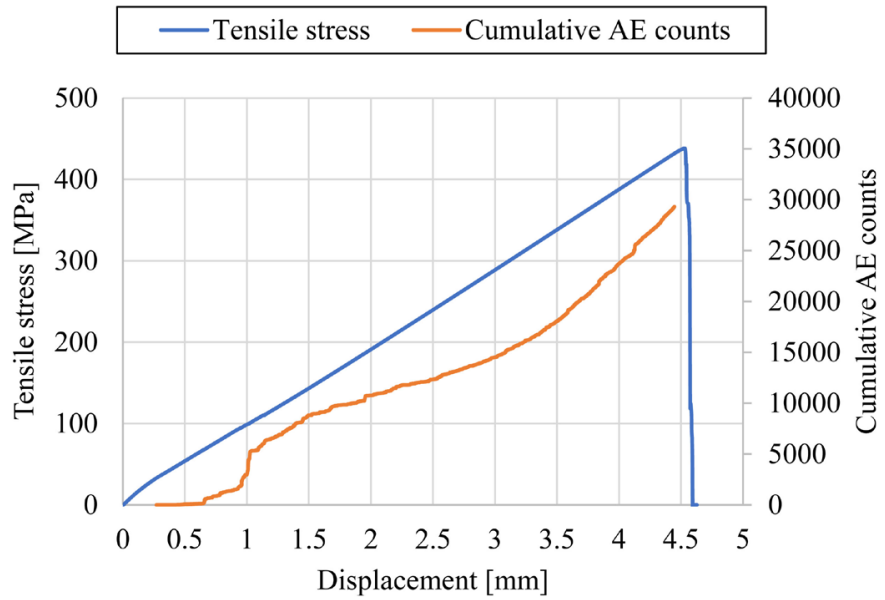

(b)

Figure 11. Results of tensile test and cumulative AE counts. (a) Stress-Strain curve; (b) Relationship between tensile stress, cumulative $\mathrm{AE}$ and displacement.

Equation (1), the corresponding strain on the tensile side of the UD layer on the bending test piece was determined, that is, at the interface between the screen type mat layer and the UD layer. According to the cross-section observation results, the distance from the outermost layer to the interface between the $90^{\circ}$ layer and the UD layer is approximately $0.62 \mathrm{~mm}$ from the intermediate surface.

$$
\varepsilon=y / \rho
$$

E. Strain;

y. displacement from neutral axis;

$\rho$ : curvature radius.

From this result, the radius of curvature at a strain of 0.011 corresponding to high AE energy generation is $108 \mathrm{~mm}$, and the corresponding stress value at this time is approximately $32 \%$ of the bending strength. From this, it can be concluded that the initial rupture stress in the UD layer shows similar values in both the bending test and the tension test. 

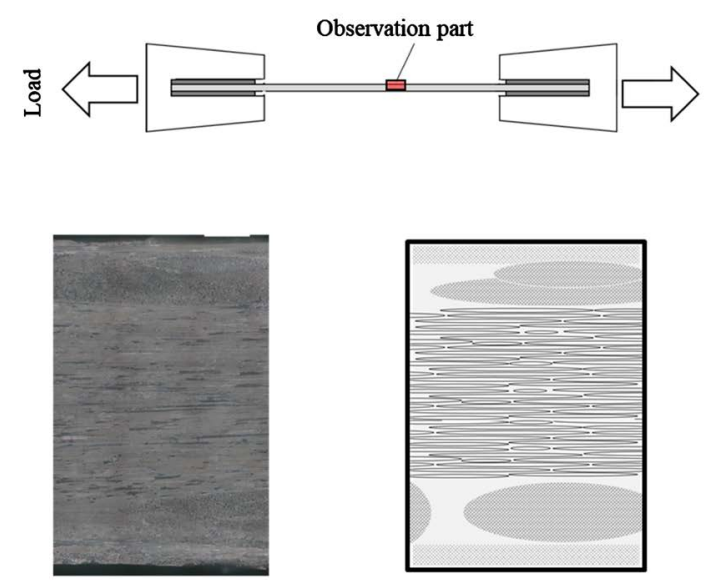

(a)
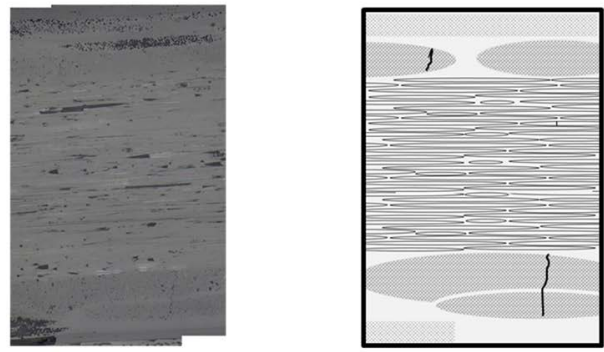

(b)

Figure 12. Cross-section observation and schematic diagram on each displacement in tensile test. (a) $0 \mathrm{~mm}$ (Specimen A); (b) $1.8 \mathrm{~mm}$ (Specimen B).

\subsection{Relationship between Initial Fracture and Fatigue Limit}

The results of tensile fatigue tests are presented in Table 4 and Figure 13. The S-N diagram shows a linear tendency, and when the cyclic stress is $25 \%$ of the tensile strength, the number of cycles exceeds $10^{7}$ times. From this point, $25 \%$ of the maximum strength can be regarded as the fatigue limit. The initial fracture stress during the tension test was $26 \%$ of the maximum strength and thus matches with the fatigue limit. This suggests that the fatigue limit obtained from the results of the tensile fatigue test and the initial fracture stress obtained from the tensile test are equivalent. In other words, it is possible to predict the fatigue limit by examining the stress at initial fracture which is the cause of the final failure by the AE method.

\section{Conclusions}

This study showed the relationship between the initial fracture stress and fatigue limit of glass fiber reinforced unsaturated polyester resin specimens. Bending test and tensile test were performed with acoustic emission (AE) measurements. Fracture mechanism was investigated by interrupted tensile test and observation. Tensile fatigue test was conducted to clarify the relationship between fatigue properties and initial fracture stress. The following conclusions were obtained in this study: 


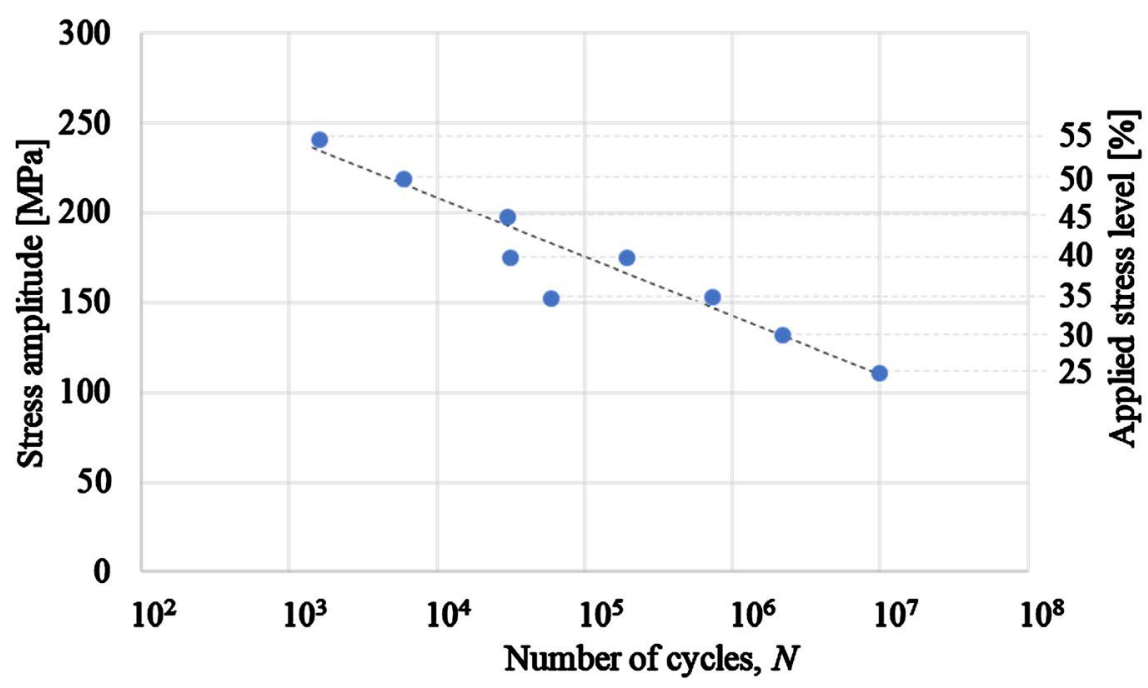

Figure 13. Relationship between stress amplitude, applied stress level and number of cycles.

Table 4. Fatigue test results.

\begin{tabular}{ccc}
\hline $\begin{array}{c}\text { Amplitude stress level } \\
{[\%]}\end{array}$ & $\begin{array}{c}\text { Stress amplitude } \\
{[\mathrm{MPa}]}\end{array}$ & $\begin{array}{c}\text { Number of cycles } \\
\text { (\% }\end{array}$ \\
\hline 55 & 241 & $1.6 \times 10^{3}$ \\
50 & 219 & $6.0 \times 10^{3}$ \\
45 & 198 & $3.0 \times 10^{4}$ \\
40 (No. 1) & 175 & $3.1 \times 10^{4}$ \\
40 (No. 2) & 175 & $1.9 \times 10^{5}$ \\
35 (No. 1) & 152 & $6.0 \times 10^{4}$ \\
35 (No. 2) & 152 & $7.3 \times 10^{5}$ \\
30 & 132 & $2.2 \times 10^{6}$ \\
25 & 110 & $1.0 \times 10^{7}$ \\
\hline
\end{tabular}

1) The initial fracture stress value obtained from quasi-static tensile testing is very close to the fatigue limit value obtained by tensile fatigue testing.

2) The fatigue limit of the material can be predicted from the initial fracture stress during static mechanical testing.

3) The AE method is effective in detecting the initial fracture.

\section{Conflicts of Interest}

The authors declare no conflicts of interest regarding the publication of this paper.

\section{References}

[1] Hannappel, R. (2017) The Impact of Global Warming on the Automotive Industry. AIP Conference Proceedings, 1871, Article ID: 060001. 
https://doi.org/10.1063/1.4996530

[2] Mamalis, A.G. and Spentaz, K.N. (2013) The Impact of Automotive Industry and Its Supply Chain to Climate Change; Somme Techno-Economic Aspects. European Transport Research Review, 5, 1-10. https://doi.org/10.1007/s12544-013-0089-x

[3] Ishikawa, T. (2015) Overview of Carbon Fiber Reinforced Composites (CFRP) Applications to Automotive Structural Parts, Focused on Thermoplastic CFRP. Journal of the Japan Society for Precision Engineering, 81, 489-493.

https://doi.org/10.2493/jispe.81.489

[4] Turner, T.A., Harper, L.T., Warrior, N.A. and Rudd, C.D. (2008) Low-Cost Carbon-Fibre-Based Automotive Body Panel Systems: A Performance and Manufacturing Cost Comparison. Proceedings of the Institution of Mechanical Engineers Part D: Automobile Engineering, 222, 53-63. https://doi.org/10.1243/09544070JAUTO406

[5] Friedrich, K. and Almajid, A. (2012) Manufacturing Aspects of Advanced Polymer Composites. Applied Composite Materials, 20, 107-128.

https://doi.org/10.1007/s10443-012-9258-7

[6] Czél, G., Jalalvand, M. and Wisnom, M.R. (2016) Design and Characterization Advanced Pseudo-Ductile Unidirectional Thin-Ply Carbon/Epoxy-Glass/Epoxy Hybrid Composites. Composite Structures, 143, 362-370. https://doi.org/10.1016/j.compstruct.2016.02.010

[7] Pandita, S.D., Huysmans, G., Wevers, M. and Verpoest, I. (2001) Tensile Fatigue Behavior of Glass Plain-Weave Fabric Composites in On- and Off-Axis Directions. Composites Part A, 32, 1533-1539. https://doi.org/10.1016/S1359-835X(01)00053-7

[8] Padmaraj, M.H., Vijaya, K.M. and Dayananda, P. (2019) Experimental Study on the Tension-Tension Fatigue Behavior of Glass/Epoxy Quasi-Isotropic Composites. Journal of King Saud University_Engineering Science. https://doi.org/10.1016/j.jksues.2019.04.007

[9] Echtermayer, A.T., Engh, B. and Buene, L. (1995) Lifetime and Young's Modulus Changes of Glass/Phenolic and Glass/Polyester Composites under Fatigue. Composites, 26, 10-16. https://doi.org/10.1016/0010-4361(94)P3624-A

[10] Kenane, M. and Benzeggagh, M.L. (1997) Mixed-Mode Delamination Fracture Toughness of Unidirectional Glass/Epoxy Composites under Fatigue Loading. Composites Science and Technology, 57, 597-605. https://doi.org/10.1016/S0266-3538(97)00021-3

[11] Feng, H. and Yi, W. (2017) Propagation Characteristics of Acoustic Emission Wave in Reinforced Concrete. Results in Physics, 7, 3815-3819. https://doi.org/10.1016/j.rinp.2017.09.060

[12] Fotouhi, M., Fragassa, C., Fotouhi, S., Saghafi, H. and Minak, G. (2019) Damage Characterization of Nano-Interleaved CFRP under Static and Fatigue Loading. Fibers, 7, 13. https://doi.org/10.3390/fib7020013

[13] Aggelis, D.G. (2011) Classification of Cracking Mode in Concrete by Acoustic Emission Parameters. Mechanics Research Communications, 38, 153-157. https://doi.org/10.1016/j.mechrescom.2011.03.007

[14] Arumugam, V., Kumar, C.S., Santulli, C., Sarasini, F. and Stanley, A.J. (2011) A Global Method for the Identification of Failure Modes in Fiberglass Using Acoustic Emission. Journal of Testing and Evaluation, 39, 954-966. https://doi.org/10.1520/JTE103730

[15] Imai, Y., Fortin, G., Pinpathomrat, B., Nishitani, K., Memon, A., Yang, Y., Ohtani, A. and Hamada, H. (2019) Quasi-Static Flexural Properties of a Pultruded Glass Fi- 
ber/Unsaturated Polyester Square Pipe. Open Journal of Composite Material, 9, 271-284. https://doi.org/10.4236/ojcm.2019.93016

[16] Qiao, P. and Yang, M. (2006) Fatigue Life Prediction of Pultruded E-Glass/Polyurethane Composites. Journal of Composite Materials, 40, 815-837.

https://doi.org/10.1177/0021998305055549

[17] Liang, S., Gning, P.B. and Guillaumat, L. (2012) A Comparative Study of Fatigue Behavior of Flax/Epoxy and Glass/Epoxy Composites. Composites Science and Technology, 72, 535-543. https://doi.org/10.1016/j.compscitech.2012.01.011

[18] Fotouhi, M., Suwarta, P., Jalavand, M, Czel, G. and Wisnom, M. (2016) Detection of Fibre Fracture and Ply Fragmentation in Thin-Ply UD Carbon/Glass Hybrid Laminates Using Acoustic Emission. Composites: Part A, 86, 66-76.

https://doi.org/10.1016/j.compositesa.2016.04.003

[19] Cao, X. and Lee, J. (2003) Control of Shrinkage and Final Conversion of Vinyl Ester Resins Cured in Low-Temperature Molding Process. Journal of Applied Polymer Science, 90, 1486-1496. https://doi.org/10.1002/app.12649 